\title{
Climate adaptation of listed buildings: an interaction between design, regulations and energy efficiency
}

\author{
Arda Karasu $^{1 *}$, Yaser Hantouch ${ }^{1}$, and Claus Steffan ${ }^{1}$ \\ ${ }^{1}$ Technische Universität Berlin, Fakultät VI, Fachgebiet Gebäudetechnik und Entwerfen, Str. des 17 Juli 152, 10623 Berlin
}

\begin{abstract}
Energy retrofitting of listed buildings requires a rethink as it is economically and technically complicated to retrofit. The Technische Universität Berlin has 47 buildings with a total net floor area above $500.000 \mathrm{~m}^{2}$ in its central campus, and $60 \%$ of them are listed. In Germany, optimizing the energy efficiency of such buildings has not to fulfill the requirements of the energy efficiency regulations. On the one hand, this situation is not corresponding to the national objectives regarding climate adaptation. On the other hand, they have to be retrofitted because of issues like poor energy efficiency and user comfort, and not privileged with special regulations. However, instead of changing the regulations, it is possible to solve the problem by changing the way of thinking. In this regard, rather than retrofitting such buildings directly, a new approach has been developed where the surrounding climatic conditions are optimized. Hereby, a simulation-based concept has been developed with an external transparent envelope. This "climate envelope" creates an intermediate space between outdoor and indoor, where through controlled air movement and passive solar gains, the balance in seasonal energy efficiency can be kept economically without any implementation on the buildings according to the building thermal and CFD simulations. This overall approach activates the yet not exploited capacity of energy savings by listed buildings using intelligent design and saves up to $30 \%$ more of primary energy.
\end{abstract}

\section{Introduction}

Various universities in Germany, among them the Technische Universität Berlin (TU-Berlin), have been running $R \& D$ projects within the energy-efficient campus framework that is funded by the Federal Ministry of Economic Affairs and Energy [1]. TU-Berlin has developed in the first stage of the project HCBC: Hochschulcampus Berlin- Charlottenburg (2016-2018) various concepts in terms of enhancing the energy efficiency of the whole campus [2]. During the ongoing second stage of the HCBC project, selected concepts have been developed further for realization. As the majority of the campus buildings are listed, a new concept has been developed to avoid restrictive containment, and finally reach the energy transition goals.

\subsection{Energy transition in Germany}

Regarding the greenhouse reduction or energy efficiency goals, there are different percentage rates in the EU or at the national level that are changed frequently.

According to Federal Ministry for the Environment, Nature Conservation and Nuclear Safety, 55\% greenhouse reduction in comparison to the year 1990 should be achieved till 2030, in a breakdown by sector 66$67 \%$ in building sector till 2030, whereas energy supply is the main actor in this sector [3]. Further, within the energy efficiency strategy program for buildings, the government aims to reduce primary energy demand by $80 \%$ compared to the 2008 level [4].

On the one hand, the greenhouse emissions in the building sector in Germany have been reduced 31,7\% between 1990-2017, and in 2017 it was $14,6 \%$ of total greenhouse emissions. Nevertheless, public buildings do not belong to the group that contributes to this statistic. On the other hand, the heating energy demand for buildings has decreased $6,3 \%$ between 2008-2016, and the trend is a $20 \%$ reduction in 2020 [5].

Berlin has a program called "Berlin Energy and Climate Protection Programme 2030 (BEK)" that aims at a climate-neutral city [6]. According to the report in 2018 of BEK, the building sector in Berlin accounts app. $49 \%$ of $\mathrm{CO}_{2}$ emissions in the city and it is aimed to reduce this amount by $85 \%$ till 2050 . As a result of this, concepts as district level play an important role [7].

Furthermore, according to the Berlin Energy Transition law $\S 8$, the state Berlin aims comprehensive energy retrofit of public buildings, where building with a net floor area above $250 \mathrm{~m}^{2}$ should have $20 \%$ less final energy demand and $80 \%$ less primary energy demand in 2050 compared to 2010 [8]. The German Energy Agency (DENA) stated, the recent annual rate of energy retrofitting of buildings is not high enough to reach the

\footnotetext{
* Corresponding author: karasu@tu-berlin.de
} 
goals [9], and German Institute for Economic Research has confirmed the situation [10].

\subsection{The approach "re-thinking"}

If we consider all the facts mentioned in section 1.1, there is a gap between the goals and the reality, and reaching the goals with state-of-the-art solutions seems to be not possible that leads to re-think how to deal with this issue. The aim is to sustain defined qualities by the preservation of listed buildings with the question, how we can set the energy free, and this also literally, so that making a success of the current conflict between building culture, comfort, and energy efficiency is possible. By adopting this approach, a building complex within the university campus has been selected for an in-depth analysis, where a retrofitting concept has been developed through building simulations.

\subsubsection{The site}

The south campus is listed as a historic ensemble because of its unique urban interaction. A representative building complex within the south campus has been chosen to analyze the approach "re-thinking". This building complex consisting of five buildings faces on one side the main building of the university and on the other side of the street the development area of the university with new buildings. Five buildings are divided into two building blocks with an alley between and face south-east. Four of them are over 100 years old, apart from one attachment building built in 1995. They represent a good example of buildings with red-yellow brickwork combinations. that are made of exposed brickwork with an air layer in the middle. All building consists of halls/labs in a different size, lecture rooms, and small for 156 employees and 122 students. The overall surface area reaches above 12,000 $\mathrm{m}^{2}$ that is divided into $3,753 \mathrm{~m}^{2}$ roof surfaces, $7,605 \mathrm{~m}^{2}$ external walls, and $1,334 \mathrm{~m}^{2}$ windows.

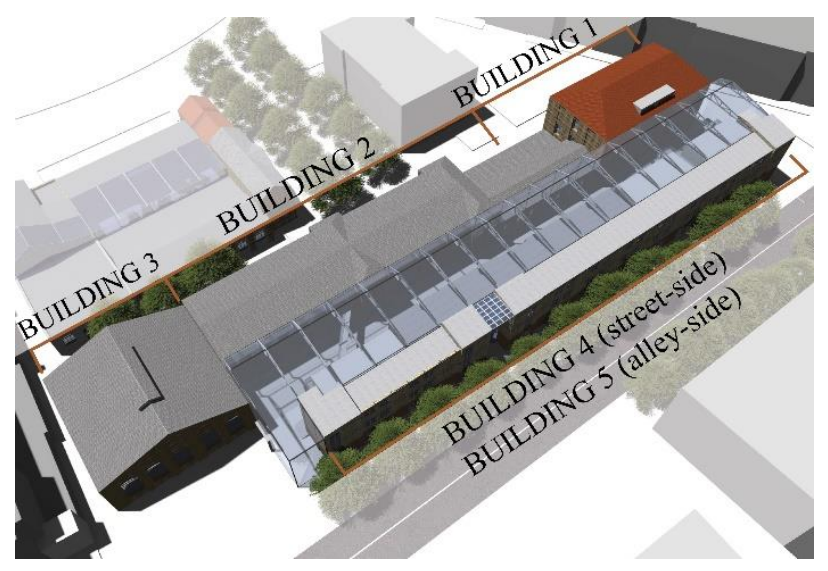

Fig. 1 The allocation of the buildings on the site

They are rather small buildings and their energy consumption is not high compared to the largest

\footnotetext{
${ }^{\text {a }}$ EnEV Energieeinsparverordnung: German regulation for energy saving in buildings
}

consumers on the campus. Nevertheless, as they all five together are considered as one building complex in the campus, their potential contribution to the energy savings is not negligible. The energy consumption of this building complex for heating is app. $1 \mathrm{GW} /$ year that corresponds to $1,7 \%$ of the final energy consumption of the whole campus. The smallest building (B3) has the worst energyefficiency, and the building (B4) that should be covered with the climate envelope is the largest consumer in the building complex.

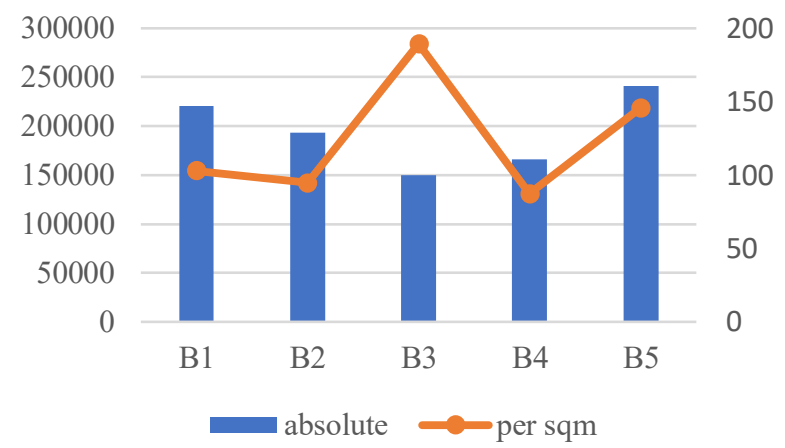

Fig. 2 Energy consumption of the existing buildings (Left in $\mathrm{kWh}$, right in $\mathrm{kWh} /$ year per net floor area)

\subsubsection{State of the art of retrofitting by listed buildings}

To have a significant contribution to the energy savings and the goal of decarbonization, the total area above $12 \mathrm{~T}$ $\mathrm{m}^{2}$ should be retrofitted. Nevertheless, there are insulation restrictions, which means the fact, where subsequent heat insulation is not possible due to economics, regulations, or building physics. Because of this fact, listed buildings are privileged by $\S 24$ and $\S 25$ of the $E n E V$ a thus, the EnEV applies not to them.

It is assumed that heat loss due to the insulation restrictions will cause $16-23 \%$ of the national heating demand in Germany despite many opportunities to retrofit external walls with exposed brickwork, such as with thin ceramic plates looking like original bricks or additional insulating layer that includes facing bricks [11]. However, one is related to potential structural damage, and the other one with enhanced construction volume issues [12]. An alternative to external insulation could be the internal one, which is more challenging regarding building physics because of thermal bridge possibilities [13]. A thickness between $4-10 \mathrm{~cm}$ WLG $035^{\mathrm{b}}$ is the spectrum for the best energy efficiency [14]. Another option is cavity insulation, where insulation material is blown into the cavity between two bricklayers. Because of problems like corrosion due to not stainless anchors in the air gap between two bricklayers, the irregular mortar between bricks, and other materials that reduce the gap, this type of measure should be implemented in exceptional cases [15].

\subsubsection{Retrofitting with Climate envelopes}

\footnotetext{
${ }^{\mathrm{b}}$ WLG : German classification for insulation materials that describes the thermal conductivity category
} 
With state-of-the-art measures reaching a high energy efficiency by listed buildings is rarely possible [16]. In this regard, retrofitting $12,000 \mathrm{~m}^{2}$ surface is neither economically nor in terms of energy efficient that leads to re-think how to retrofit such buildings. The answer could be to optimize the climate while creating a warmer microclimate with a transparent envelope. This so-called climate envelope (CE) is a permanently climate-adapted space, that is described as a combination of a building with an additional transparent external envelope. The envelope is utilized as an architectural means of adapting to climate change and to mitigating the effects thereof. Further information about the concept and it's both energy related and economic benefits can be found in the previous publication of the authors[17,18].

\subsubsection{Climate Envelope Examples}

There are numerous building additions/extensions with similar transparent envelopes, especially in the EU. With the same principles as preserving historical substance and achieving energy efficiency, the architects added a glass addition in front of the central railway station of Strasbourg in France. The same office has also designed a similar entrance building for the Luxembourg Central Station, where they used this time ETFE instead of glass. Although not directly with energy efficiency-related, but as additions to historic buildings, there are also examples in Berlin like the extension of the Jewish Museum by Santiago Calatrava and the roof of the German Historical Museum by I.M. Pei. Besides historical cases, there are various contemporary buildings with the same principle as the naturhus ${ }^{\mathrm{c}}$ examples in Sweden with integrated greenhouses or Academy Mont-Cenis in Germany.

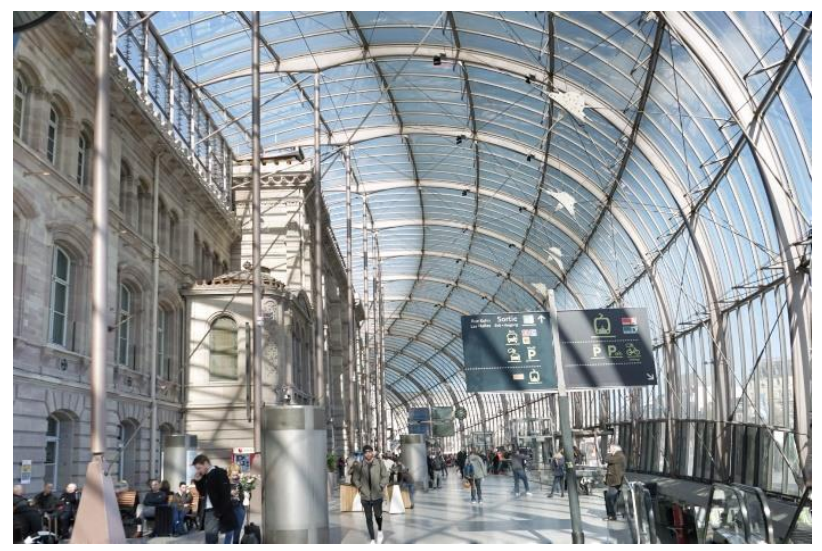

Fig. 3 Strasbourg central railway station: The historic building from 1883 has become an addition in 2007 designed by AREP Paris (Pic. CKarasu)

\section{Simulations}

This work focuses on the outputs of various simulations regarding energy efficiency and thermal influence of the CE, where Designbuilder has been used

\footnotetext{
c "House of nature" in Swedish: Houses with an integrated greenhouse that combine biological and physical principles
}

as a tool. Each five building in the complex has been modeled and simulated with and without a climate envelope to find out its influences. Extended information about the simulation methodology can be found in the previous publication of the authors.

\subsection{The influence on energy consumption}

First, assuming that it is technically possible, the u-value for new buildings according to the German building energy regulations (EnEV) has been set as a benchmark for analyzed objects to show the highest energy saving potential with state of the art measures. Accordingly, the outputs have been compared with the actual situation of the objects in combination with the climate envelope in the middle of the two building blocks. With this, the climate envelope has been simulated with various volumes that cover between 2,240-5,015 $\mathrm{m}^{2}$ of the adjacent building that corresponds up to $41 \%$ of the total surface area. The appropriate size and shape of the CE have resulted from the interaction between energy-saving potential and visibility [18]. The difference between the $\mathrm{CE}$ with the highest saving potential and the CE with adjusted shape according to the preservation regulations amounts to $2.7 \%$.

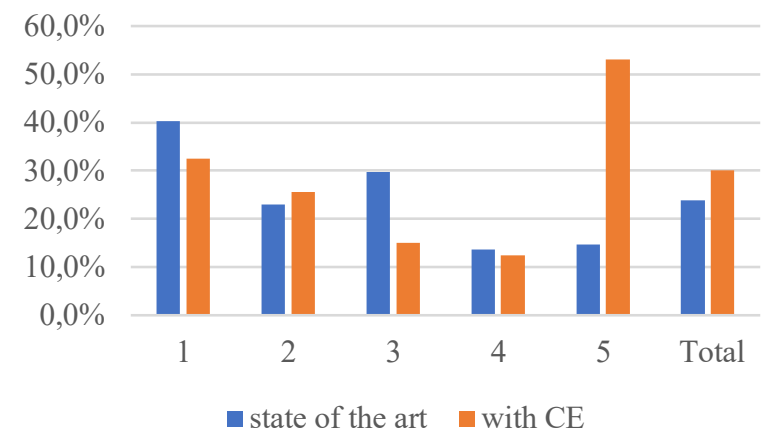

Fig. 4 Comparison of energy saving potential (final energy) of the buildings (1-5) between regular retrofitting and climate envelope for each building

The spatial interaction of all buildings with the climate envelope is different that leads to different energy savings. As seen in Fig. 4, building 3 with the less adjacent area to the climate envelope benefits the least. In comparison, building 5 is entirely under the climate envelope, which almost quadruples the potential energy savings. According to the simulations results, it is possible to reduce the primary energy for heating over 580T kWh/a that corresponds to a $1 \%$ reduction in the whole campus. The savings include the energy substitution through PV panels on the roof of building 5 . The cooling consumption is only $4.2 \%$ of the all energy consumption of the building complex and the minimal changes through climate envelope is neglectable.

into an organism living in symbiosis with inhabitants and nature, source: www.ecolrelief.se 


\subsection{The influence on temperature difference}

As Santamouris et al. declared, the heat island phenomenon may occur during the day or the night period. The intensity of the heat island is mainly determined by the thermal balance of the urban region and can result in up to 10 degrees of temperature difference [19]. It could have a negative effect on the cooling load of the buildings, whereas the temperature difference could reduce the energy demand for heating. A climate envelope acts as an artificial urban heat island that aims to enhance the temperatures precisely preventing overheating through natural ventilation.

By enhancing the air temperature in the intermediate space and reducing the air movement, the DT between outdoor, in this regard the climate envelope, and the indoor air temperature drops down that leads to energy savings by heating. According to the simulation results, the monthly DT between outdoor dry-bulb temperature and the operative temperature under the climate envelope is $7.16^{\circ} \mathrm{C}$, whereas it is slightly higher with $9.3^{\circ} \mathrm{C}$ during the daytime. As can be seen in Fig. 5, the temperature difference under the climate envelope constantly remains a minimum $7^{\circ} \mathrm{C}$ higher, and on average $9.75^{\circ} \mathrm{C}$.

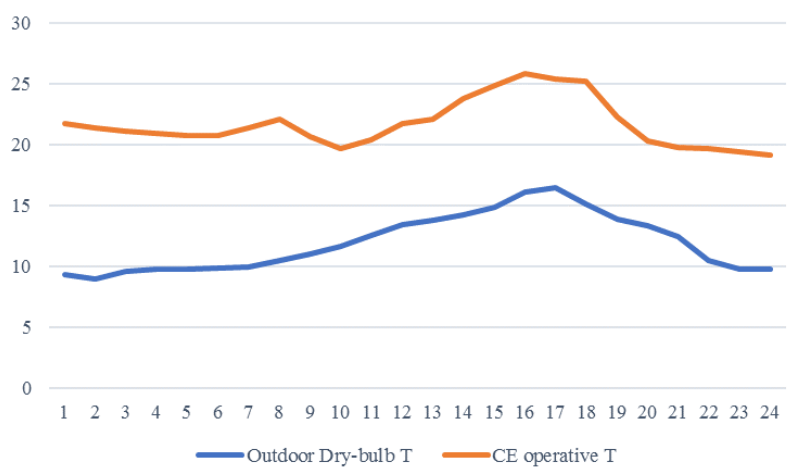

Fig. 5 Example day for temperature curve during one day

As Sadineni et al. stated, infiltration is driven by a pressure difference across the building envelope caused due to the temperature difference between indoor and outdoor air (stack effect), wind movement [20]. The climate envelope influences the infiltration rate by enhancing the temperature and reducing the indoor airspeed. According to the simulation results, the CE let increase the indoor operative temperature of the room towards the $\mathrm{CE} 0.41^{\circ} \mathrm{C}$ during working hours.

\subsection{Spatial and temporal expansion}

Higher temperatures in the climate envelope enable additional spaces that can serve various purposes, which corresponds to a temporary area up to approximately $1,000 \mathrm{~m}^{2}$ between two building blocks and $300 \mathrm{~m}^{2}$ as roof extensions in this case. Simulations have been run with DesignBuilder to find out the time slot for the usage of this new space.
In the real case, the space between two blocks is a small street just for vehicles and not used for other purposes. In the test reference year (2018), the outside dry-bulb temperature is above $18^{\circ} \mathrm{C}$ for 81 days. Thirty of them were rainy according to the statistics ${ }^{\mathrm{d}}$. Considering other weather issues like wind and the noise factor would not allow using this space for other purposes during the rest of 51 days. Fig. 6 shows clearly that a $\mathrm{CE}$ expands the usable time of the area between two blocks 131 days as it acts as a noise and weather barrier.

It is evident that within these 166 days above $18^{\circ} \mathrm{C}$ under the climate envelope, there will be temperature fluctuations according to the solar radiation difference by cloudy or rainy days. This situation should be a criterium while designing appropriate working spaces that could temporarily be adjusted in terms of quick temperature drops.

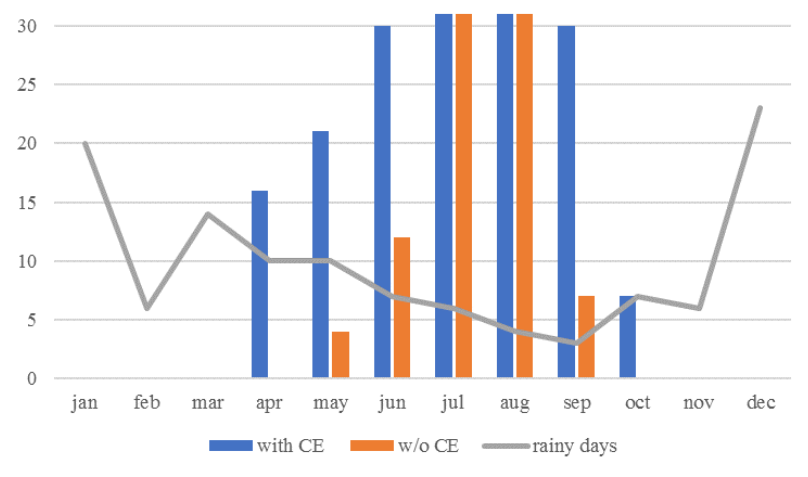

Fig. 6 Number of days above $18^{\circ} \mathrm{C}$ in the space between two building blocks

\subsection{Controlled natural ventilation}

CFD and thermal comfort simulations have been run to determine the size and position of the openings on the climate envelope to enable sufficient air circulation to keep comfort conditions. In this regard, the following criteria have been analyzed by the simulations with the scope of maximum thermal comfort without draught and minimum visible interference:

- opening size and position on the vertical walls,

- opening size and location on the roof of the CE,

- entrance situation on the sidewalls,

- and the air circulation around the extensions on the roof of the existing buildings.

The vertical surfaces of the climate envelope are 810 $\mathrm{m}^{2}$, and the roof surfaces $1,695 \mathrm{~m}^{2}$. The regulation set a requirement of at least $10 \%$ ventilation openings together in both higher and lower parts of the unheated glass extensions, in this case, on the climate envelope. By the CFD simulations, various opening size in a range of 10 $20 \%$ that corresponds to $250-500 \mathrm{~m}^{2}$ respectively have been simulated.

\footnotetext{
${ }^{\mathrm{d}}$ http://www.wetter-berlin-online.de/Statistik-Daten.htm
} 

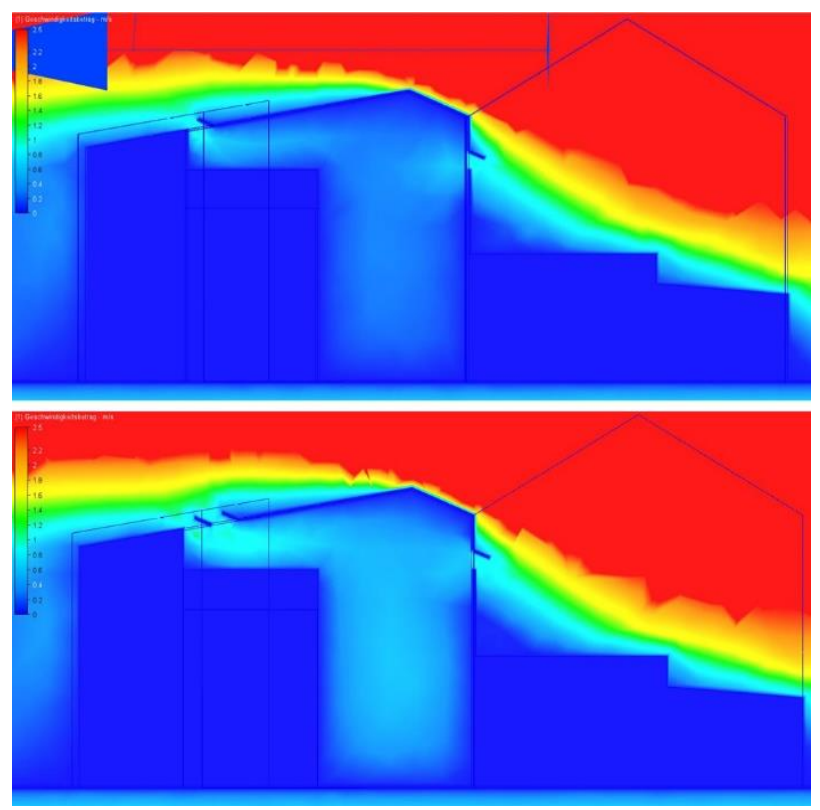

Fig. 7 Opening one line of roof windows lead to smoother air distribution during the transition period (upper section), whereas opening two lines of windows for an accelerated air exchange

Sidewalls, respectively, the entrances are problematic to regulate as they have to fulfill the following criteria:

- enabling frequent access (and evacuation) of people without a negative impact on natural air circulation.

- allowing entrance for fire-fighting vehicles according to the $\S 5$ of the Berlin Building Regulations, which is at least $3 \mathrm{~m}$ wide and $3,5 \mathrm{~m}$ high.

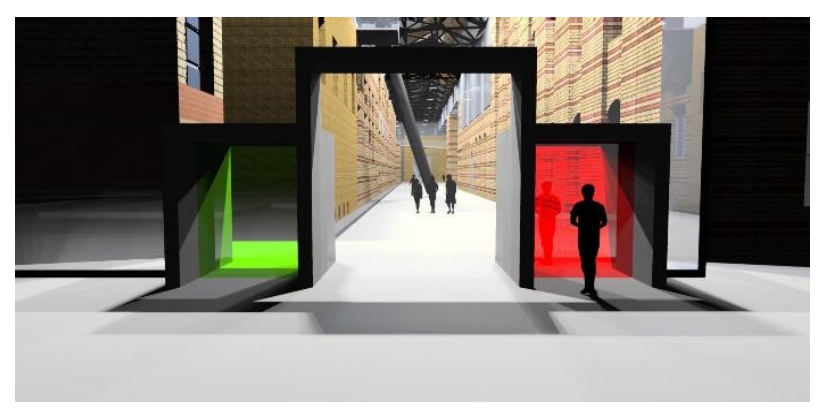

Fig. 8 The entrance situation with two openings for people and in the center for a vehicle. In winter, they are closed and in summer, fully open during working time.

Using one entrance may cause a correlation that disturbs the optimum operation. In this regard, the gates have been separated. For the more frequented one, there were two options as having a revolving door or a vestibule. A revolving door has been eliminated as its round shape is not adequate for the whole design. Creating two vestibules separating the entrance and exit allows more controlled air circulation.

Further, the building extensions on the roof of the existing building on the south block are directly under the roof of the climate envelope and should be designed to avoid overheating where the DIN 4108-2 Norm describes minimum requirements on heat protection in Part II.
According to the Norm, as Berlin is in the climate region $\mathrm{B}$, the operative indoor temperature in critical rooms is not allowed to exceed $26^{\circ} \mathrm{C}$ more than $500 \mathrm{~h} / \mathrm{a}$. These $500 \mathrm{~h}$ correspond to the operating time between 7 am- 6 pm and the calculations should base on TRY 2011. A further requirement shading for northern windows automatically by over $150 \mathrm{~W} / \mathrm{m}^{2}$ irradiance and additionally a passive cooling system as described in the figure have been applied. The simulations have been run with TRY 2018 that is hotter in comparison to TRY 2011. According to the simulation results, the indoor temperatures exceed $26^{\circ} \mathrm{C}$ rarely, and the regulatory requirements are fulfilled.
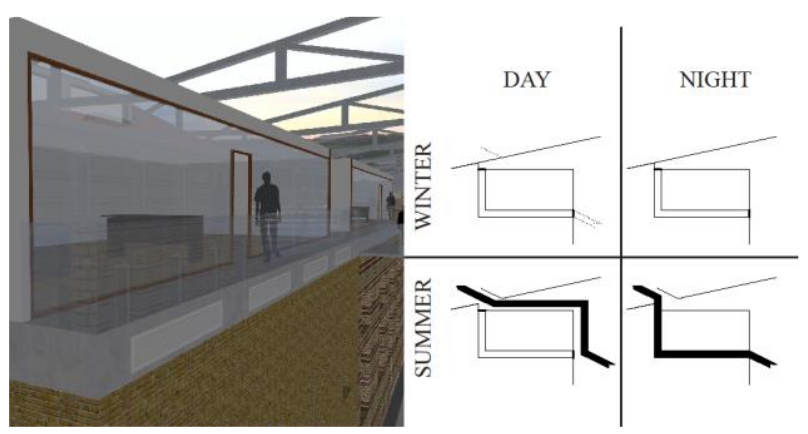

Fig. 9 Natural ventilation concept for the building extensions

\section{Conclusion}

From the energy supply perspective on, to achieve and even outreach the national and local goals regarding carbon neutrality in the campus is highly possible, as the TU Berlin is supplied with district heating that has a primary energy factor of $0,45^{\mathrm{e}}$ and green electricity with zero carbon footprint. However, the final energy consumption would remain the same. From a consumer perspective, a real contribution to environmental issues should be saving on final energy while retrofitting buildings.

In order to exploit the final energy saving potential of the campus buildings, any contribution is necessary. This paper proves that novel approaches like climate envelopes should be considered as alternatives to retrofit listed buildings because of the following advantages in the particular case:

- They lead to at least $6.3 \%$ more energy-efficiency with $22 \%$ less investment compared to state-of-the-art measures.

- The new construction surface is fivefold less than surfaces to be retrofitted. That leads to faster implementation and this without the allocation of the employees or students.

- New spaces up to $1,300 \mathrm{~m}^{2}$ result from adding a transparent envelope for various usages.

In conclusion, there is an ongoing study to develop further climate envelopes within the campus to improve its transferability to newer buildings, and the airflow

\footnotetext{
e The recent primary energy factor from the local supplier Vattenfall in 2019
} 
between indoor and the climate envelope to control the draft effect.

This research is a part of the project EnEff: $H C B C 1$. Umsetzungsphase funded by the German Federal Ministry for Economic Affairs and Energy, Ref. \# 03ET1632A

\section{References}

1. H. Erhorn-Kluttig, S. Doster, H. Erhorn. Der energieeffiziente Universitätscampus: Pilotprojekte de Forschungsinitiative EnEff:Stadt. Bonn: Fraunhofer IRB Verlag. (2016)

2. M. Kriegel, C. Steffan, F. Ziegler, C. NytschGeusen, A. Karasu, B. Münch, Y. Hantouch. Eneff: HCBC HochschulCampus Berlin - Charlottenburg Demonstration eines innovativen Wärmeenergiemanagements für ein Bestandsquartier. (2019)

3. Bundesministerium für Umwelt, Naturschutz und nukleare Sicherheit. Klimaschutzplan 2050: Klimaschutzpolitische Grundsätze und Ziele der Bundesregierung. (2019)

4. BMWI. Energiewende Bauen 2017: Forschung zu effizienten Technologien und intelligenten. Berlin: Forschungszentrum Jülich $\mathrm{GmbH}$ Projektträger Jülich. (2017)

5. Bundesministerium für Umwelt, Naturschutz und nukleare Sicherheit. Klimaschutz in Zahlen: Fakten, Tredns und Impulse deutscher Klimapolitik. (2019)

6. Senatsverwaltung für Umwelt, V. u. Berliner Energie- und Klimaschutzprogramm 2030 (BEK 2030) . (2019)

7. Senatsverwaltung für Umwelt, V. u. Bericht zur Umsetzung des Berliner Energie- und Klimaschutzprogramms, Berichtsjahr 2018. (2019)

8. Berliner Energiewendegesetz. Berlin, Berlin: GVBl. 122 (2016)

9. R. Westermann, T. Bründlinger, O. Krieger, C. Müller. DENA Gebäudereport Kompakt 2019: Statistiken und Analysen zur Energieeffizienz im. (2019)

10. P. Singhal, J. Stede. Wärmemonitor 2018: Steigender Heizenergiebedarf, Sanierungsrate sollte höher sein. (2019)

11. P. Jochum, P. Mellwig, F. Bülbül, M. Pehnt, L. Brischke, M. Jarling, M. Kelavic. Technische Restriktionen bei der energetischen Modernisierung von Bestandsgebäuden. (2012)

12. S. Himburg. Von bauphysik.tu-berlin.de: https://www.bauphysik.tuberlin.de/menue/forschung/keram_belaege/keramis che_belaege_auf_wdvs/abgerufen (2008)

13. M. Krus, K. Sedlbauer, H. Künzel. Innendämmung aus Bauphysikalischer Sicht. Fachtagung "Innendämmung - eine bauphysikalische Herausforderung". (2005)
14. G. Kolbe. Innendämmung, aber richtig. Mauerwerk, European Journal of Masonry, 102-106 (2012)

15. N. Altaha. Zweischalige Außenwände Wärmetechnische Fassadensanierung mit Sichtmauerwerk nach der neuen EnEV. Mauerwerk European Journal of Masonary, 7, 210-214 (2003)

16. C. Conrad, P. Häupl, H. Petzold. Energetisch und bauphysikalisch optimierte Sanierung eines Baudenkmals in Görlitz. Bauphysik 29, 221-230 (2007)

17. A. Karasu, M. Buchholz, C. Steffan. Building with Climate Envelopes. Berlin: Universitätsverlag. (2013)

18. A. Karasu, Y. Hantouch, C. Steffan. Simulationbased energy efficiency retrofit of listed building ensembles: An alternative solution with a climate envelope. BS Cairo: Simulation for Sustainable built environment. (2019)

19. M. Santamouris, N. Papanikolaou, I. Livada, I. Koronakis, C. Georgakis, A. Argiriou, D. N. Assimakopoulos. On the impact of urban climate on the energy consumption of buildings. Solar Energy, 70, 201-216.

20. S. Sadineni, S. Madala, R. Boehm. Passive building energy savings: A review of building envelope components. Renewable and Sustainable Energy Reviews, 3617-3631 (2011) 